\title{
From Johann to Maurice: Science and Expression in the Philosophical Praxis of Medicine
}

\author{
Timm Heinbokel ${ }^{1}$ (D)
}

Accepted: 3 August 2021 / Published online: 18 October 2021

(C) The Author(s) 2021

\begin{abstract}
Phenomenology's return to lived experience and "to the things themselves" is often contrasted with the synthesized perspective of science and its "view from nowhere." The extensive use of neuropsychological case reports in Merleau-Ponty's Phenomenology of Perception, however, suggests that the relationship between phenomenology and science is more complex than a sheer opposition, and a fruitful one for the praxis of medicine. Here, I propose a new reading of how Merleau-Ponty justifies his use of Adhémar Gelb and Kurt Goldstein's reports on Johann Schneider for his phenomenology of embodied perception. I argue that for Merleau-Ponty these neuropsychological case reports represent a coherent deformation of the intercorporeally expressed existence of Schneider that through speech fall again onto the common ground of perception, thereby allowing Merleau-Ponty to understand, in the equivalent sense delivered by language, Schneider's total being and fundamental illness. I then discuss what Merleau-Ponty's method implies for a phenomenological praxis of medicine, and for the role of science in this praxis.
\end{abstract}

Keywords Phenomenology · Maurice Merleau-Ponty $\cdot$ Medicine $\cdot$ Science . Physician-patient encounter

\section{Introduction}

In his foreword to Donald Landes' translation of Phenomenology of Perception, Taylor Carman, after identifying Merleau-Ponty as "a phenomenologist first and foremost," gives a brief definition of phenomenology: it is "an attempt to describe the

Timm Heinbokel

timm.heinbokel@charite.de

1 Department of Pathology, Charité - Universitätsmedizin Berlin, Charitéplatz 1, 10117 Berlin, Germany 
basic structures of human experience and understanding from a first-person point of view, in contrast to the reflective, third-person perspective that tends to dominate scientific knowledge and common sense." ${ }^{\prime}$ Characterizing Merleau-Ponty vis-à-vis his predecessors Edmund Husserl, Martin Heidegger, and Jean-Paul Sartre, Carmen then states that "Merleau-Ponty regularly drew from the empirical findings and theoretical innovations of the behavioral, biological, and social sciences" (Carman 2012: vii). While both statements taken by themselves seem to be valid and accurate introductory remarks, their juxtaposition brings to the forefront a startling incoherence: if phenomenology is the description of experience from a first-person point of view, how can Merleau-Ponty, classified in the same breath as phenomenologist par excellènce, use the third-person findings of the empirical sciences that precisely served to distinguish phenomenology from the natural sciences?

Merleau-Ponty in fact offers remarkably little explicit reflection on his methodology apart from the foreword to his book, written after the completion of his work, and a few brief sections in the third chapter of the second part, where he introduces the case of Johann Schneider. We will see that, despite their brevity, these remarks will allow us to read Merleau-Ponty's new mode of analysis, which he terms existential analysis, as an attempt to stress a genetic or constructive aspect of phenomenology over purely transcendental approaches. The insights Merleau-Ponty gives us into the actual praxis needed for this existential analysis, however, receive little explicit elaboration in these remarks. To render intelligible the praxis and methodological validity of existential analysis, we will first have to turn to the gestural theory of meaning and the intercorporeal intersubjectivity that Merleau-Ponty develops throughout the remainder of Phenomenology of Perception. How Merleau-Ponty was able to perform his analysis without personally encountering Schneider will then, in a second step, be made clear by understanding the status Merleau-Ponty implicitly accords to the neuropsychological case reports through his theory of expression, which is developed most clearly in two essays nearly contemporaneous with his Phenomenology of Perception.

Phenomenological approaches to the praxis of medicine, as exemplified by Merlau-Ponty's use of Schneider, have commonly been constructed in opposition to the "scientific" and "objectifying" gaze of modern medicine. To adequately position Merleau-Ponty's new mode of analysis within the tension between phenomenology and science, we will therefore need to begin by sketching phenomenology's critique of science. Having then retraced Merleau-Ponty's steps in his approach to Schneider, I will argue that the scientific gaze understood as a coherent deformation within the context of Merleau-Ponty's theory of expression allows us to re-integrate scientific praxis into a phenomenological praxis of medicine, in this way giving it the philosophical roots that are increasingly hard to grasp.

\footnotetext{
${ }^{1}$ Carman (2012), viii. The translation of Phenomenology of Perception by Robert Landes (MerleauPonty 2012) will be cited throughout this article, with further references given as in-text citations preceded by the abbreviation PhP. The French will be cited from Merleau-Ponty (2005).
} 


\section{What is Phenomenology?}

Characterizing phenomenology and science in terms of opposing and contradictory forces as exemplified by Carman's foreword seems to be justified by the critique of science with which Merleau-Ponty prefaces his Phenomenology of Perception. Indeed, much of his argumentation throughout the book, continuing the work he began in The Structure of Behavior, is arguably dedicated to bringing empiricism and intellectualism to their logical conclusions, showing how the scientific perspective is in the end nothing but "naïve and hypocritical" as it will always remain "abstract, signitive, and dependent" with regard to the world that is always implied yet never mentioned, ignoring the prior perspective of consciousness "by which the world first arranges itself around me and begins to exist for me" ( $P h P$ lxxii). In contrast to this, the entire effort of phenomenology, according to Merleau-Ponty, is to "rediscover this naïve contact with the world in order to finally raise it to a philosophical status" $(P h P 1 \mathrm{xx}){ }^{2}$ Pushing the prevailing scientific perspectives to their extremes, Merleau-Ponty is in the same movement thus led back to phenomenology.

A similarly nuanced relationship between science and phenomenology is found in Edmund Husserl's Crisis of the European Sciences, as presented by Merleau-Ponty in one of his later lectures: The human sciences adopted the attitude that external structures and causal relations were fully explanatory of the phenomena in question-ultimately undermining themselves, since the claims of the human scientist must then also be reduced to external causes. ${ }^{3}$ This means for philosophy, if it does not want to flee to logicism and posit a realm of truths in themselves that are unassailable by psychologism, that it needs to assure itself that it is not merely the effect of contingent and accidental causes. Husserl's answer was to place the very possibility of the human and natural sciences and philosophy itself upon the foundation of the phenomenological reduction (Merleau-Ponty 2010: 319f.). This epochē, in Husserl's concept of transcendental phenomenology, then allows us to reach our genuine experience of the world in its appearing through a bracketing off of our theories and beliefs about the world. From within this bracketed experience, one can gain a genuine Wesensschau of essences, reaching a purified realm of consciousness, the transcendental ego. The problem of the sciences thus indeed reaches to the very core, the very task of phenomenology.

It is worth bearing in mind, though, that Merleau-Ponty wrote Phenomenology of Perception at a time when gaining access to Husserl's texts was relatively difficult, which would explain why he does not provide any extensive exegesis of Husserl in his book (Landes 2013b: 149). His foreword, written after the completion of his

\footnotetext{
${ }^{2}$ As will become clearer throughout the remainder of this article, Merleau-Ponty aims to take contigent structures of experience into account—without however giving up essentialist claims about the structure of experience.

3 The issue of Merleau-Ponty's reading of Husserl is, of course, complex, and I have to limit myself to specific aspects without any discussion of the validity of Merleau-Ponty's reading of Husserl. A useful and relatively recent introduction can be found in Toadvine and Embree (2002).
} 
thesis, contains in fact the most explicit commentary on Husserl's thought. And it is precisely here that we encounter his famous remark that "the most important lesson of the reduction is the impossibility of a complete reduction" (PhP lxxvii). At the end of the reduction and all phenomenological reflection, we do not reach an all-encompassing thought and the transcendental ego, but being-in-the-world [êtreau-monde] that is in and toward the world (PhP lxxviii). Thus, Merleau-Ponty cites as "perhaps the best formulation" of the phenomenological attitude Eugen Fink's description of a "standing in wonder before the face of the world" (PhP lxxvii). Such an attitude can never completely cut its ties to the world, and phenomenology then indeed "suspends the affirmations of the natural attitude" only to arrive at a "direct description of experience such as it is" ( $P h P$ lxx). Consequently, yet paradoxically, in this direct description of lived experience, phenomenology becomes an "exact science" $(P h P$ lxx $)$. Biology, psychology, sociology, the entire universe of science, is constructed upon this lived world, and remains only a "second-order expression" of the experience that phenomenology returns to: "I am the absolute source" (PhP lxii). ${ }^{4}$ It is only in ourselves that we will find the "unity" and the "true sense [sens]" of phenomenology, this "myth" that only "allows itself to be practiced and recognized as a manner or as a style" ( $P h P$ lxxi).

Given Merleau-Ponty's own critique of the sciences complicated by his critical stance toward Husserl's transcendental phenomenology-in the last analysis for Merleau-Ponty a form of idealism - he seems to be more sympathetic to the kind of genetic or constructive phenomenology Husserl mentions in his final works, in which aspects of our experience that cannot be simply constituted by an isolated pure transcendental ego are taken into account $(P h P$ lxx). For Husserl, this would lead to an investigation into the historical genesis of certain aspects of our experience or of cultural institutions such as language, and Merleau-Ponty in his foreword indeed briefly highlights how connecting with a history of a doctrine by "putting the causes and the sense of a doctrine back into an existential structure" can complete Husserl's Sinngenesis and teach us "what the doctrine 'means' [veut dire]" (PhP lxxxiii). More importantly, he offers an insight into the methodology applied to Schneider's case when he distinguishes "phenomenological 'understanding", from the kind of "classical 'intellection"” phenomenology itself is not immune against, with phenomenological understanding finally allowing phenomenology to become "a phenomenology of genesis" (PhP lxxxii). This kind of phenomenological understanding is aimed at "grasping the total intention," and "the unique manner of existing expressed in the properties of the pebble, the glass, or the piece of wax, in all of the events of a revolution, and in all of the thoughts of a philosopher" (PhP lxxxii). For the purpose of "the disclosure [révélation] of the world" that is all phenomenology — this seeing of "the world anew" that is all "true philosophy"-a story [une histoire racontée] is able to "signify the world with as much 'depth' as a philosophical treatise," Merleau-Ponty concludes (PhP lxxxv).

\footnotetext{
4 We encounter already at this point Merleau-Ponty speaking of science in terms of expression. While this notion will be developed throughout the remainder of the present article, see Fóti (2013) for a study that traces expression in Merleau-Ponty's work with reference also to science.
} 
We have thus discovered the problem of the sciences, this seeming opposition between science and phenomenology, to be woven tightly into the fabric of the nature and task of phenomenology. We can already see that Merleau-Ponty's use of neuropsychological case reports serves a bigger purpose than just delivering instrumental examples: his phenomenology was aimed at adequately accomodating these conditions. The discipline of phenomenological pschopathology, perhaps inaugurated by Karl Jaspers and including names such as Medard Boss, Ludwig Binswanger, Eugene Minkowski, and Hubertus Tellenbach, takes this up and strives to give an adequate account of mental disorders by integrating natural science and phenomenology. ${ }^{5}$ Phenomenology's ability to illuminate mental disorders, however, seems to be implicitly taken for granted in this, and the philosophical implications are by and large not problematized. The present study is thus not primarily interested in discussing the specific conclusions about the structure of experience in mental disorder that Merleau-Ponty arrives at, but rather: How does Merleau-Ponty claim to grasp the "total intention" and "the unique manner of existing" of Johann Schneider? ${ }^{6}$ How does he claim to do this through the only link he has with Johann Schneider, the case reports by Gelb and Goldstein? And what does this tell us in turn about the relationship between science and phenomenology in the praxis of medicine?

Merleau-Ponty's own account in Phenomenology of Perception would seem to represent itself as our best resource in trying to uncover the philosophical implications of these questions. Tacitly relying on the scientific accounts of Schneider, Merleau-Ponty will find himself using the very sources and the very thinking he aims to lead ad absurdum. Yet precisely this movement leads him back to phenomenology, and the phenomenological understanding of these sources, he claims, can be used to contribute to a genetic phenomenology. Taken as such, however, Merleau-Ponty makes startling claims and delivers little explanation for statements often shrouded in deeply metaphorical language. Merleau-Ponty himself has raised the stakes, and suggests that the answer to our questions will lead us to the heart of phenomenology, and indeed true philosophy itself.

\section{Johann Schneider}

We will begin by turning to the first part of Phenomenology of Perception, "The Body," in which Merleau-Ponty in a few brief sections gives us insights into his methodological thinking. After dedicating two chapters to brief refutations of mechanistic physiology and intellectualist physiology, Merleau-Ponty sets himself to study the body in spatiality, sexuality, and speech in order to arrive at his own

\footnotetext{
5 Fernandez (2019) offers a very useful introduction from the perspective of psychopathology. The famous Zollikon seminars, given by Martin Heidegger and organized by Medard Boss, are translated in Heidegger (2001). Contemporary, more general introductions to the discipline are available in Stanghellini et al., (2019) as well as Tekin and Bluhm (2019). Important contributions from the perspective of medicine in general are Leder (1990), Zaner (1981), Young (1997), Varela, Thompson, and Rosch (1991), Duden (1993). A useful contemporary introduction is Toombs (2001).

${ }^{6}$ For an illustration of how Merleau-Ponty's conclusions about the structure of experience are still the subject of contemporary debate, see Romdenh-Romluc (2007), Dreyfus (2007).
} 
positive account of the body in lived experience. It is at this point that MerleauPonty introduces Johann Schneider, and it is this part of Phenomenology of Perception that will allow us, as a first step, to render intelligible the praxis and methodological validity of Merleau-Ponty's new mode of analysis.

The case of Johann Schneider was first published by Adhémar Gelb und Kurt Goldstein in their 1918 study "Zur Psychologie des optischen Wahrnehmungs- und Erkennungsvorganges." In that work they deliver an initial detailed description of the case: Schneider had suffered a deep wound to the back of his head while serving in the German army, with the tissue damage reaching into the occipital region of his brain and likely damaging his visual cortex. Over four pages, Gelb and Goldstein give a dense report of basic clinical and psychological examinations, followed by four chapters of further tests and examinations aimed at analyzing various aspects of Schneider's complex case. Merleau-Ponty cites their work from a 1920 book that includes Gelb and Goldstein's initial work together with subsequent articles that detail further tests and analyses of Schneider (Gelb and Goldstein 1920). He most often refers to the article "Über den Einfluß des vollständigen Verlustes des optischen Vorstellungsvermögens auf das taktile Erkennen," in which Gelb und Goldstein have already started to investigate the impact of Schneider's visual impairments on other senses such as touch.

Presented as a case of visual agnosia, Schneider is most notably unable to follow the experimenters' instructions for abstract and imaginary movements, and instead has to continually adapt his initial inadequate attempts to the spoken instructions in an ongoing and "genuine act of interpretation" (PhP 133). Revisiting Schneider's case from several angles throughout the chapter, and using various aspects of the case description by Gelb and Goldstein to prove the inadequacy of either an empiricist or intellectualist interpretation, Merleau-Ponty finally is able to conclude that in the normal subject "the life of consciousness - epistemic life, the life of desire, or perceptual life-is underpinned by an 'intentional arc' that projects around us our past, our future, our human milieu, our physical situation, our ideological situation, and our moral situation, or rather, that ensures that we are situated within all of these relationships" (PhP 137). ${ }^{7}$ Rather than being bodies with the ability to move ourselves, motricity presents an originary mode of intentionality, and an oriented way of being-in-the-world: a being-in-the-world not of an "I think" but of an "I can" $(P h P 139){ }^{8}$ Therefore, "we must not say that our body is in space, nor for that matter in time. It inhabits space and time" (PhP 140).

Shortly after introducing the intentional arc, Merleau-Ponty in fact names the method through which he arrived at this conclusion: "The study of a pathological case has thus allowed us to catch sight of a new mode of analysis-existential

\footnotetext{
7 As Matherne (2014) has pointed out, the term "intentional arc" ("intentionaler Bogen" in German) is borrowed from then-contemporary literature on schizophrenia, specifically Fischer (1930), who takes it from Beringer (1926).

${ }^{8}$ For a more thorough discussion of Merleau-Ponty's concept of motor intentionality, see Kelly (2000), Jensen (2009).
} 
analysis - that goes beyond the classical alternatives between empiricism and intellectualism, or between explanation and reflection" ( $P h P 138)$. The precise procedure of this new mode of analysis, however, remains unexplained in this passage, and we need to turn to an earlier moment, when, in the heat of his argument, Merlau-Ponty divulges some revealing remarks. Just six pages into his initial presentation of Schneider, he asks: "How are we to make sense of this series of facts, and how should the function that exists for the normal person, but that is missing for the patient, be understood through them?" (PhP 110) The solution, he continues, cannot be to simply transfer to the normal subject that function which the patient is trying to recover. Instead, illness, just like childhood, is "a complete form of existence," meaning that normal functions and pathological functions cannot be neatly delineated ( $P h P 110)$. Deficiencies cannot be simply deduced from their substitutions, but instead the substitutions must be taken as they are, and as "allusions to a fundamental function that they attempt to replace, but of which they do not give us the direct image" (PhP 110). The appropriate method is thus not a "method of differences," but consists in "correctly reading phenomena, in grasping their sense, that is in treating them as modalities and variations of the subject's total being" (PhP 110). While grasping the total being of the subject—as imbued by its illness, which is a complete form of existence-the variations that can be detected in substitutional behavior have in turn to be used as indirect images alluding to fundamental troubles.

In the middle of the chapter, at the end of a section in which he argues that the described symptoms cannot be understood through causal explanations connected to visual disability, Merleau-Ponty for a second time ventures to give an explanation of his method. Possibly also in conversation with Gestalt psychology, ${ }^{9}$ he writes that behavior cannot be grasped by causal thought, but only by a kind of thought that "takes its object in its nascent state, such as it appears to him who lives it" (PhP 122). This kind of thought thus recognizes the genetic aspect of behavior, yet also strives to see in the first-person perspective of the one "who lives it." This analysis, he continues, also has to take into account the total being of the subject, grasping "the atmosphere of sense by which it is enveloped," and seeking to "slip itself into this atmosphere." This type of thought, Merleau-Ponty concludes, must discover, "behind dispersed facts and symptoms, the total being of the subject in the case of the normal person or the fundamental disorder in the case of the patient." Again we see Merleau-Ponty stressing the total being of the subject, which is the foundation of "the atmosphere of sense" that envelops the subject. He also explicitly states the necessity to "slip into" this atmosphere and see behavior in the first-person perspective of the one "who lives it." Only in this way the total being or the fundamental disorder can be discovered.

At another instance, after a lengthy discussion of reflexive or intellectualist analysis of illness and the inevitable attempts to go back to causal explanations when doctors and psychologist become frustrated with the former's generalizing tendencies, Merleau-Ponty seems to tie his argumentation back to the remarks we had studied

\footnotetext{
${ }^{9}$ For an introduction to Merleau-Ponty's engagement with Gestalt psychology, see Embree (1980). For another study also with reference to Edmund Husserl, see Heinämaa (2009).
} 
in his foreword: "so long as phenomenology has not become genetic phenomenology, then these offending retreats into causal thought and naturalism will remain justified" (PhP 128). A genetic phenomenology, on the other hand, would be able to link "the origin and the essence of the disorder," and find the "concrete essence or structure of the illness that expresses both its generality and its particularity" ( $P h P$ 128). This seems to be the clearest indication that Merleau-Ponty sees his new kind of analysis applied to Schneider's case as a contribution to genetic phenomenology: through a study of the origin of Schneider's disability, he is able to arrive at the essence of his disability, and this essence is able to articulate both the generality and the particularity of Schneider's total being and his underlying illness.

Merleau-Ponty, through his "new mode of analysis," a peculiar balance of the general and the particular, a third-person and a first-person perspective, thus pursues a method that recognizes illness as a complete form of existence, correctly reads the subject's total being, takes in the atmosphere of sense by which it is enveloped-and that at the same time is able to understand substitutions as indirect images alluding to fundamental dysfunctions and can slip itself into the atmosphere of sense to see behavior in the first-person perspective of the subject who lives it. This is the fundamental task Merleau-Ponty sees himself accomplishing in his own analysis of Schneider, as his contribution to a genetic phenomenology that is able to grasp both the generality of a subject and the particularity of an illness. Using his foreword, we could see his existential analysis as kind "phenomenological "understanding"" (PhP lxxii), an extension of the phenomenological description to arrive at a genetic and not purely transcendental phenomenology. The overall trajectory seems just as well to be in line with a sentence from Merleau-Ponty's foreword which we have already cited in part: "As the disclosure of the world, phenomenology rests upon itself, or rather, founds itself" ( $P h P$ lxxxv). Leading empiricism and intellectualism to their absurd conclusions, he arrives at phenomenology — through phenomenology. Importantly, given the centrality of his account of motor intentionality, his analysis is precisely not aimed at refining the philosophical foundations of psychopathology, but at accomodating the fact that a mental disorder affects motor, cognitive, affective, linguistic, and perceptual abilities_-in short, Schneider's “total being." Merleau-Ponty indeed strives to arrive at a structure of experience that accomodates mental disorder, yet at the same time makes explicit why psychopathology can be grasped by another person in the first place: because it is a "complete form of existence." This, notably, makes Merleau-Ponty's intervention philosophically relevant not only for psychopathology and psychiatry, where it has historically been met with the most interest, but for the praxis of medicine on the whole-wherever two persons meet with the intention that one of them discerns both the generality of a subject and the particularity of an illness. ${ }^{10}$

\footnotetext{
${ }_{10}$ This makes the fact that Merleau-Ponty does not rescind all essentialist claims about the structure of experience so important when using his insights for the praxis of medicine. In turn, we might argue that contemporary medicine, which under the heading of "personalized medicine" aims through the accumulation of vast amounts of high-resolution diagnostic measurements to arrive at a singular diagnosis for every unique patient, is potentially and paradoxically giving up its claim to be a science.
} 
Having given a dense description of his new mode of analysis, Merleau-Ponty however does not elaborate how the praxis of this new analysis is to be accomplished. On what basis would one be able to correctly read Schneider's total being and take in the atmosphere of sense that envelops him? And how would one then be able to slip into that atmosphere of sense to see Schneider's behavior as he does, to understand the allusions that his substitutions make toward his fundamental underlying illness? To begin to substantiate these startling claims, we will have to see how Merleau-Ponty in the following chapters develops an intersubjectivity based on a gestural theory of meaning that unites linguistic and corporeal signification.

\section{Gesture}

In the subsequent chapter, discussing the synthesis of the body, Merleau-Ponty stresses that the unity of the lived body must not be achieved by conceiving of the body as a constituted object, but rather by comparing it to a work of art (PhP 151). Just like a novel, a poem, a painting, or a piece of music are "beings in which the expression cannot be distinguished from the expressed, whose sense is only accessible through direct contact, and who send forth their signification," so our body is "a knot of living significations" that is able to perform an integrated "single gesture" (PhP 153). Continuing with the same analogy, there is equally no need to posit a transcendental ego that synthesizes the body. Rather, as a system of motor power and perceptual powers, the body is not an object for an "I think," but "a totality of lived significations that moves towards its equilibrium" (PhP 155). This equilibrium, this work of art, is at the same time never completed, never accomplished: "a new knot of significations" can be formed, reorganizing our equilibrium and fulfilling "our blind expectation" (PhP 155).

After this approach to the lived experience of the body through spatiality and thus motricity, Merleau-Ponty offers an account of how affects such as desire and love are equally able to make objects and beings exist for us, with the same argumentation furthering his thought on expression ( $P h P$ 156). Indeed, as he will be able to conclude a little later, sexual life is "original intentionality" that just like perception and motricity grounds the intentional arc and haunts every experience, without - contrary to what psychoanalysis would make us believe-reducing that experience to sexuality ( $P h P 160)$. This "atmosphere" (PhP 171) continuously present in human life is just like the unity of the body a function of expression, for "the body continuously expresses existence." It is the "total existence" that is expressed, through a "primordial operation of signification" in which the expressed cannot be divided from the expression, in which the signs themselves induce their sense just like "speech expresses thought" ( $P h P 171)$.

It is then by turning to the phenomenon of speech and the simple observation that "the word has a sense" $(P h P 182)$ that Merleau-Ponty aims to "definitely move beyond empiricism and intellectualism" ( $P h P$ 182). After discovering in both motricity and sexuality an intentionality and a power of signification, the same, he begins, can be said of the deliberate act of signification, speech: the designation of an object does not happen after recognition but is "recognition itself," and indeed, for 
pre-scientific thought, "to name an object is to bring it into existence or to modify it" (PhP 183). Then, again through the study of conditions such as aphasia, anarthria, and color blindness, Merleau-Ponty is able to arrive at the conclusion that speech and thought simply cannot be held apart-rather, "speech accomplishes thought" ( $P h P$ 183). Speech and thought are enveloped in each other, so that sense is caught in speech. Much like the expression cannot be distinguished from the expressed in the work of art that is the body, speech becomes "the external existence of sense" (PhP 187). Here, Merleau-Ponty can briefly turn to material expressions of thought and speech: successful expression in the form of a text "makes the signification exist as a thing at the very heart of the text," bringing to life an organism of words (PhP 188). What is more, this signification is installed in both writer and reader "like a new sense organ" and "opens a new field or a new dimension to our experience," thus giving expression a power over both sender and recipient that goes well beyond mere epistemic reception ( $P h P$ 188). The same seems to hold true for any kind of aesthetic expression, which "confers an existence in itself upon what it expresses, installs it in nature as a perceived thing accessible to everyone" ( $P h P 188)$.

These aspects of speech and thought, and indeed expression as such, are then united to their fundamentally corporeal reality through the concept of gesture. As my thoughts are accomplished by speech and aesthetic expression is accessible to everyone, so also the speech of others accomplishes my thoughts: "Through speech, then, there is a taking up of the other person's thought, a reflection in others, a power of thinking according to others" (PhP 184). The words are meaningful not through a second-order recognition of a dictionary meaning, but because we live in a world in which speech is already "instituted," and I can take up available significations in a new expression ( $P h P$ 189). Through this common world, "speech is a gesture, and its signification is a world" (PhP 190). Just as I can perceive things only through my body, so also do I understand the other person through my body, and the understanding of gestures is achieved through reciprocity "as if the other person's intention inhabited my body, or as if my intentions inhabited his body" (PhP 191). The "sense" of the gesture understood in this way is not behind the gesture, but "it merges with the structure of the world that the gesture sketches out and that I take up for myself" ( $P h P$ 192). Indeed, "the sense of the gesture spreads across the gesture itself" and "the linguistic gesture, like all others, sketches out its own sense" (PhP 192). It is thus the body "that shows, that speaks."

\section{Intercorporeality}

This expressive unity of the body that underlies the fundamental equivalence of corporeal and linguistic gestures is powerfully developed by Merleau-Ponty into a theory of intersubjectivity in the last chapter of the subsequent part of Phenomenology of Perception, "Others and the perceived world." Central to his argumentation will be how the intentional orientation of the embodied consciousness structures the world according to sedimented previous human actions. For behavior descends into nature and is deposited there in the form of a cultural world, which allows one to "experience the near presence of others under the veil of anonymity" in cultural 
objects (PhP 363). The very first cultural object, and the one by which all other cultural objects come into existence, is then the other's body as the bearer of a behavior (PhP 364). Any analysis of the perception of others in the cultural world must resolve "the paradox of a thought that resides in the exterior and that, when compared to my own, is already without a subject and is anonymous" ( $P h P$ 364).

This is a paradox that objective thought again finds itself unable to resolve in its attempts to somehow suture "my phenomenal body onto the primordial world" (PhP 366). The antinomies of objective thought that appear when it tries to understand the traces in the world left by a being-for-itself in a being-in-itself can only disappear, Merleau-Ponty continues, when we conceive of consciousness not as a constituting consciousness and a pure being-for-itself, but as a perceptual consciousness whose perception is inherent in things, and a being inserted into the world that is the subject of a behavior ( $P h P$ 367). Only then "will another person appear in control of his phenomenal body and receive a sort of "place" ( $P h P$ 367). The intuitive embodied perception I have of cultural objects, the body, and ultimately others is illustrated by an example from child psychology: when an adult playfully bites the finger of a child, the child is capable of moving his mouth in imitation, knowing the possibilities for movement that are presented on the outside and immediately understanding them as the capacity for the same intentions ( $P h P$ 368). Thus, the relationship "between my consciousness and my body such as I live it" is equal to the one that exists between "this phenomenal body and the other person's phenomenal body" — an internal relation that indeed makes the other appear as "the completion of the system" (PhP 368).

This is the intuitive relation that makes possible that my body perceives the other's body in this common world and finds "a miraculous extension of its own intentions" (PhP 370). The intuitive communication of consciousnesses takes place in and is made possible by the single world in which embodied consciousness are gathered together as "anonymous subjects of perception" ( $P h P$ 369). Just as the parts of my body form a single unified whole, so now the other's body and my body "are a single whole, two sides of a single phenomenon" (PhP 370). The element of anonymous and pre-personal existence however remains pivotal, for only if I grasp myself not through an apodictic evidentness, but rather find myself as a pre-personal subject given to itself, can I allow the other's behavior "its place in the world," neither verified as an object or falsified as a dream ( $P h P 369)$. It is this anonymous existence, of which my body remains forever the trace, that inhabits simultaneously the two bodies that have come to form a single whole and enables this mutual extension and indwelling of intentions (PhP 370). ${ }^{11}$

\footnotetext{
11 This passage brings to mind some of Merleau-Ponty's later thought on the flesh of the world: "There is no problem of the alter ego because it is not I who sees, not he who sees, because an anonymous visibility inhabits both of use, a vision in general, in virtue of that primordial property that belongs to the flesh, being here and now, of radiating everywhere and forever ..." (Merleau-Ponty 1968: 142). While any contextualization with respect to the remainder of Merleau-Ponty's work lies beyond the scope of the present study, it might be worthwile to keep in mind one of his working notes to The Visible and the Invisible: "The problems posed in phenomenology of perception are insoluble because I start there from the 'consciousness' - 'object' distinction', (Merleau-Ponty 1968: 200). That his later thought is not in contradiction to Phenomenology of Perception has been argued by Landes: "The structure of a "universal
} 
The difficulties of perceiving others do however not all cease with the discovery of behavior, but for the discovered and understood anonymous life to become an open life and another person, the perception of the cultural object of language plays an essential role ( $P h P$ 370). Objective thought and the resulting unicity of the cogito cannot be brushed away as simple fictions. Yet, ultimately, solipsism and communication are revealed to be but the two sides of the same problem: solipsism could only be wholly true if someone would be "observing his existence without being anything and without doing anything" ( $P h P$ 378). This is surely impossible, since to exist is to be in the world ( $P h P 378)$. If I encounter a stranger who has not yet uttered a word, I might well believe that he lives in "another world," but "should he utter a word, or merely make an impatient gesture, then he already ceases to transcend me" (PhP 378, emphasis my own). The other's gaze only transforms me into an object if we both establish an inhuman gaze and we each sense our actions as observed "like the actions of an insect," and language, this instituted and sedimented cultural object in the cultural world of human actions, is able to constitute that common situation in which neither speaker is the sole master or the sole slave (PhP 378).

Existence as being-in-the-world, the sheer fact that I am something and that I do something assembles my existence into behavior in the form of corporeal or linguistic gestures. And precisely because I am a being in the world, "as soon as existence gathers itself together and engages in a behavior," it inevitably "appears to perception [elle tombe sous la perception]" (PhP 378). The fundamental ambiguity of the subject, its impurity and anonymous existence in the body, is precisely that which, once it necessarily assembles itself in behavior, makes it appear to perception and thus to the other. The negative ambiguity of existence is turned into the positive ambiguity of expression, for "the presence to myself (Urpräsenz) that defines me and that conditions every external presence is simultaneously a depresentation (Entgegenwärtigung) and throws me outside of myself" (PhP 381). There is never a static coincidence neither with myself nor with the other-the moment when I fully understand myself "can never arrive" and "I am never at one with myself" (PhP 362). Yet this same "ambiguous life where the Ursprung of transcendences takes place" is what puts me into communication and is what "makes knowledge possible" (PhP 382).

The embodied consciousness engenders and constitutes communication and intersubjectivity, in the immediate and ultimately also personal encounter in the one world, which is the cultural world of sedimented human action that is structured by the gestural significations of movement and speech. The relation of my consciousness to my body is the paradigm for the relationship between my phenomenal body and the other phenomenal body, the system being completed through the ground of perception on which both fall. As speech accomplishes thought and my own thought is accomplished by the other's speech, the mutually anonymous inhabitation of intentions is ultimately transformed into an open, personal encounter.

Footnote 11 (continued)

flesh" of the world is, then, not a rejection of the gestural theory of meaning worked out in Phenomenology of Perception, it is the outcome of this thought carefully taken up through the deepening account of the paradoxical logic of expression and the experience of intercorporeality" (Landes 2013a: 176). 
We can now see how Merleau-Ponty deemed possible his new mode of analysis, the "correct reading of phenomena" $(P h P 110)$ in a phenomenological understanding that goes beyond transcendental phenomenology, towards a constructive, genetic phenomenology. On the basis of his intuitive and immediate intersubjectivity in which expression is united to the expressed in an integrated corporeal and linguistic gesture, Merleau-Ponty's claim to be able to grasp the sense of a subject's total being and to correctly read phenomena to the understanding of indirect images of fundamental illness is at least rendered coherent. His striking call to grasp the atmosphere of sense that envelops the subject, to slip into this atmosphere to see the subject's behavior as he himself lives it, all this can now be read against Merleau-Ponty's description of the body as this expressive unity that shows and speaks, with even the linguistic gesture spreading its sense across the gesture itself. The transition from an epistemic description to a phenomenological understanding now seems effortless for the encounter of embodied consciousnesses that naturally assemble themselves in behavior, expressing their total existence, and falling under each other's perception in the common world where "everything resides" (PhP 204).

When the embodied consciousness of Schneider assembles itself in behavior, it is impossible to limit the expression of his illness to psychopathology, but precisely allows those striving to arrive at a phenomenological understanding of his total being and his fundamental illness to rely on an intuitive and intercorporeal intersubjectivity that is based on a gestural understanding of meaning. What is more, we can now admit the cultural world of sedimented human action into the mutually anonymous inhabitation of intentions, including when the two embodied consciousnesses are those of a patient and his doctor. This begins with the banal examples of a blood-stained shirt or an unused walking cane, but continues with lab results, case reports, even tissue samples and diagnostic imaging, all of which we can classify as artefacts of sedimented human action. Having left the confined discipline of psychopathology and having entered the field of corporeal intersubjectivity, Merleau-Ponty now gives us the common world where "everything resides," where action even in its sedimented form cannot but fall onto the common ground of perception.

Yet even if we were to accept these conclusions for a phenomenological grounding of medicine, how could this praxis claim to be a scientific one? To begin answering this question, we will have to confront an issue that as of now still seems to be only loosely related: Maurice Merleau-Ponty never met Johann Schneider. How, then, was Merleau-Ponty able to slip into the "atmosphere of sense" that enveloped Schneider, how was he able to decipher the indirect images that alluded to his fundamental disorder? How can he claim to use indirect, third-person evidence for his phenomenological understanding of Schneider's illness? For this we will have to turn to the status that Merleau-Ponty accords to the neuropsychological articles by Gelb and Goldstein, a status that is implicitly mentioned already in Phenomenology of Perception and that will be justified more explicitly through a brief look at two essays stemming from roughly the same phase of his work. 


\section{Expression}

We have seen above that Merleau-Ponty wrote, when he developed the notion of the body and language as gesture, that a successful expression in text makes signification "exist as a thing at the very heart of the text," and installs this signification "like a new sense organ" in both writer and reader, to open "a new field or a new dimension to our experience" (PhP 188). In an article published in 1945 (the year Phenomenology of Perception appeared), "Cézanne's Doubt," Merleau-Ponty pursues this thought to develop a powerful notion of expression that will be pivotal to understanding the authority that he grants Gelb and Goldberg's articles in his phenomenological work. ${ }^{12}$

Merleau-Ponty begins by developing an understanding of Cézanne's painting that is nothing short of a phenomenology of painting: in his exact study of appearances and a return to a pre-thetic experience of the world, Cézanne's work is able not only to express this experience, but also to engender the same kind of suspension in the one perceiving his work. Using Balzac, Merleau-Ponty characterizes Cézanne's quest as "a thought to be expressed, a system to be built, a science to be explained" $(C D 77) .{ }^{13}$ Added to this is the difficulty that a painter must not only create and express an idea, but must also "awaken the experiences which will make the idea take root in the consciousness of others" ( $C D$ 77). Yet if a work is successful, it has the power to be "self-teaching": guided by the "confused clarity of style" the reader or the spectator will find what was intended to be communicated (CD 77). The work will then have "joined together these separate lives," and will dwell "undivided in several minds, presumably in every possible mind, as an acquisition for always" ( $C D$ 77). Cézanne, any painter or writer, is thus for Merleau-Ponty able to create a work, be it a painting or a text, that makes the spectator or reader suffer the same suspension, dwelling undivided and for always in every possible mind.

By way of discussing the influence of Cézanne's life on his work, Merleau-Ponty then even offers us an understanding of the relationship between illness and expression. He opposes psychoanalytic readings of works that reduce this relationship to a total determinism, but neither is there a total freedom: the work "was announced in the life," yet artistic expression still takes up in freedom that which is given (CD 84). This expression still has a privileged relationship to illness: Cézanne's work reveals "a metaphysical sense" of his schizothymia. This is because this illness, which Merleau-Ponty describes as "the reduction" of the world to frozen experiences and "the suspension" of expressive values, becomes "a general possibility of human existence when the illness confronts consistently one of its paradoxes-the phenomenon of expression". ${ }^{14}$ The reduction and suspension, this epochē that Cézanne suffers in his illness stops being an absurd fact and destiny when it engenders expression

\footnotetext{
12 There are a number of recent studies on Merleau-Ponty's notion of expression, among them the arelady mentioned Fóti (2013), but also Landes (2013a), Bullington (2013).

13 Merleau-Ponty (2007b: 69). Further references to this text will be given as in-text citations preceded by the abbreviation $C D$.

14 About illness and the phenomenological reduction, see also Heinämaa (2002).
} 
to become available as a possibility of human existence. For Cézanne himself this means that in his schizoid temperament cause and effect "are gathered together in the simultaneity of an eternal Cézanne" that brings about the "human Cézanne"which means, in the last analysis, that "to be schizoid and to be Cézanne are one and the same thing" ( $C D$ 80). In the paradox of expression, Cézanne is able to freely take up that which imbues his total being, in order to make available as a general possibility of existence the schizothymic human Cézanne.

In "Indirect Language and the Voices of Silence," a 1952 article that was published separately after Merleau-Ponty abandoned a project that would later be published posthumously as The Prose of the World, Merleau-Ponty further develops his conception of expression for the domain of language. This time no longer in conversation with Gestalt psychology, as in Phenomenology of Perception, but more in conversation with structuralism, Merleau-Ponty again stresses that language is not an operation secondary to thought. ${ }^{15}$ Communication is not about interpretation, but about letting ourselves be structured by eloquent gestures of speech, the "fold in the immense fabric of language." 16 Language is "entirely a showing," and without a table of correspondences unveils its secrets in and by itself. Yet the idea of complete expression is thereby rendered nonsensical, for "meanings can never free themselves completely from the intercourse of signs" (ILVS 246) and expression is not the adjustment of an element of discourse to an element of sense, but remains "an operation of language upon language" which in a decentering of itself moves toward its sense (ILVS 245).

Merleau-Ponty goes on a long excursus on painting in order to investigate the privilege of the sense of language (ILVS 248). Responding to Malraux' distinction between the classical attempt to deliver an objective representation and a modern return to subjectivity, he writes that the classical perspective just as well is simply one of the ways invented for projecting the perceived world before itself, and not "the copy of that world." Modern painting therefore does not represent a problem of subjectivity, but precisely the problem of "how we are grafted to the universal by that which is most our own" (ILVS 253). The painter does not put his self, but his style in the painting, with style being a demand that issues from the perception of the painter: "perception already stylizes" (ILVS 255). Every style is a "shaping of the elements of the world," and when these data of the world are submitted to the "coherent deformation" that is style, meaning emerges (ILVS 255). It is a new system of equivalences that is established, un upheaval that breaks ordinary ties in the name of truer relations, in the name of "another world" (ILVS 257). Every coherent deformation, and this includes the attempt at objective representation, thus opens up a new "field of investigations," Merleau-Ponty continues, and the new work has that unlimited fecundity that Husserl termed Stiftung.

When the theory of perception puts the painter back into the world and into the body as spontaneous expression, then there is no need for "Hegelian monstrosities"

\footnotetext{
15 For an introduction to Merleau-Ponty's engagement with structuralism, see Schmidt (1985).

16 Merleau-Ponty (2007c: 244). Further references to this text will be given as in-text citations preceded by the abbreviation ILVS.
} 
to follow the Stiftung of a work and to understand the history of painting (ILVS 265). All perception, and in short, every human use of the body is already "primordial expression" (ILVS 267). It is this primordial expression that connects works, that orders culture and meaning in an "original order of advent" (ILVS 267). All gestures arise from a single syntax and each gesture points to a continuation or a recommencement in a "desire for total manifestation" (ILVS 274), and they converge by the single fact that they are "efforts to express" (ILVS 269). Therefore, at the very moment that I address myself to the other in expression, I do not have to choose between the pour soi and the pour autrui, between thought according to me and thought according to the other, but I and the other "are linked together without concessions" (ILVS 272).

If an author is indeed a writer, that is, if "he is capable of finding the elisions and caesuras which indicate the behavior" through his style, then what was said about painting can be applied to writing as well. The reader is able to respond the call of the writer, "even if neither of them is aware of it," and is able to join him "at the virtual center of the writing" (ILVS 276, emphasis my own). Just as with painting, the sense of a novel is perceptible "at first only as a coherent deformation imposed upon the visible" (ILVS 277). What is presented in the work is indeed able to work upon us, is capable of "decenter[ing] our image of the world," of drawing it to a fuller sense and to new relations (ILVS 277). The "exact forms of language" and philosophy are then able to express, Merleau-Ponty suggests, the essence of language even better than literature (ILVS 277). There exists a critical, philosophical, universal use of language that claims to "retrieve things as they are" and aims to retrieve an integral truth. This is possible because speech can turn back upon itself and "gain possession of itself and conquer the secret of its own inventions" (ILVS 279). Language could even be said to go beyond sketching out a coherent deformation, as it is able to not only replace one sense by another but to achieve the "substitution of equivalent sense." Despite this relative superiority, however, there can again be no meaning without signs, for the thing itself is the disappearance of all clarity (ILVS 281).

\section{Conclusions}

The emotion of strangeness that Cézanne suffers, this pre-thetic experience that makes him engage in the exact study of appearances leads him to engage in the poetry of the continual rebirth of existence, expressing in his painting the vibration of appearances and in the same movement the meaning of his schizothymic disposition. This science to be explained, this confused clarity of style is a self-teaching work that works upon the spectator, ultimately dwelling undivided and forever in every possible mind. Whether it is Cézanne's painting or the classical perspective aiming at objective representation, both remain a coherent deformation that express how the painter, the particular, is grafted onto the world, the universal-how the world touches us. This new system of equivalences in an upheaval breaks the ordinary ties of the spectator and suspends the habits of seeing in the name of truer relations and in the name of another world, in an unlimited fecundity for continuing or recommencing expression. 
What Merleau-Ponty writes about painting-even characterizing Cézanne's painting as "a science to be explained"-_does hold the possibility to reconnect with our opening remarks about the relationship between phenomenology and science, in order to place science back into the praxis of medicine. For it is a science understood within the framework of Merleau-Ponty's theory of expression that, freed from the clutter of its "received view" and given its phenomenological roots, can transform the praxis of medicine into a philosophical praxis. Patrick Heeland as aptly characterized the received view of science as follows:

...the 'received view' [of scientific medical research] begins in the life-world and ends in a meaningful construction about the life-world that takes the form of an ideal representation model of Nature. The gap between the life-world and the scientific model of Nature is bridged by a postulate, let me call it the 'mirroring postulate,' one of the same kind that is commonly thought to link geometry and the life-world. Just as geometrical objects float, as it were, off the page or blackboard and take their place in the ideal realm of the Mind, so too do scientific models or theories. (Heelan 2001: 48)

Integrating science into a phenomenological structure of experience, we may thus say: Just as the classical perspective for Merleau-Ponty is simply one of the ways invented for projecting the perceived world before itself and not "the copy of that world," so we may now free the received view of science from its heavy claim to be an objective representation, and as "coherent deformation" let it truly open up a new "field of investigations" with that unlimited fecundity we are all witnesses of. ${ }^{17}$ The praxis of medicine can thus claim to be a scientific one when, accomplishing Merleau-Ponty's movement and giving science its phenomenological roots as coherent deformation that falls onto the common ground of perception in the advent of expression, it allows its use of science to be subjected to a phenomenological analysis.

Under the analysis of phenomenology, metaphor becomes fundamental for scientific discourse - an insight that also reflects back on the status of Merleau-Ponty's own heavily metaphorical use of language throughout his work. ${ }^{18}$ It is this science in its expressive status, conveyed via the privileged means of language, that reached

\footnotetext{
17 In line with this, it is curious to note with Heelan (2001: 56) that theories of scientific progress have characterized traditions of scientific interpretation as "thought styles" (Fleck, Duden), "paradigms" (T. S. Kuhn), and "styles of scientific thinking" (Crombie).

18 Note another apt characterization by Heelan: “...perceptual space is assumed to be modeled by Euclidean geometry, colors by electromagnetic wavelengths, sounds by pitch and loudness, and syphilis by a positive Wassermann Test, when all such predications are no more than metaphors apart from the collaboration of the human senses, language, and cultural environment" (Heelan 2001: 60). Note also Paul Ricœur in the conclusion of his article "The Function of Fiction in Shaping Reality": "Our task, consequently, would be to extend the concept of fiction beyond language and the plastic arts, and to acknowledge the work of the analogies, models, and paradigms in the conceptual field of scientific knowledge. The ground for this extension has already been prepared by the interpretation of metaphor in terms of semantic innovation" (Ricœur 1979: 140). For Merleau-Ponty's metaphorical language, see Gill (1990).
} 
Merleau-Ponty in the neuropsychological case reports of Gelb and Goldstein, and that he was able to use for his existential analysis of Schneider. ${ }^{19}$ For Merleau-Ponty, the atmosphere of sense that radiates from Johann Schneider's being is the immediate result of the fundamental expression of his total existence that gathers itself together in behavior to use the one sole syntax of gestures. Schneider and his disability in this are "one and the same" as his illness imbues his total being and represents a complete form of existence, a complete work. This is what is submitted to the coherent deformation of objective representation in the works of Gelb and Goldstein, expressing through the entire showing of language their intercorporeal perception of Schneider in the confused clarity of the invented style of neuropsychology-a "second-order expression," as we have seen Merleau-Ponty write in his introduction, yet an expression nonetheless. Taking up the work that are Gelb and Goldstein's articles, although they are not aware of it (PhP 277), Merleau-Ponty is able to join them at the center of their writing, being worked upon by the work, having his image of the world decentered. The organism of the words installs its significations in Merleau-Ponty like a new sense organ (PhP 188) and opens a new dimension of his experience, breaking his ordinary ties with the world to an upheaval in the name of truer relations and another world.

When we free science from the "mirroring postulate" and give it back its metaphorical status, when we place it into the advent of expression as a coherent and unlimitedly productive deformation, then we are also able to follow Merleau-Ponty's reasoning one step further to enter into the depths of a crux that stands at the heart of both medicine and phenomology. Merleau-Ponty aims to deliver an account of the structure of experience that is able to accommodate Schneider's condition, without at the same time giving up the attempt to delimit universal aspects of the structure of experience. It is this tension which we can detect in the background of many of the passages we have examined, and it is precisely this tension which remains a configuring hermeneutic in every encounter between a patient and his physican: to discern the generality of a condition, i.e., those features shared by everyone attained by the disease, while delimiting the particularity of a condition, i.e., those features that are distinct in an individual's presentation of the disease. Both medicine and phenomenology in their philosophical praxis thus remain an ongoing attempt of negotiating the universal and the particular.

To see how Merleau-Ponty's paradoxes of expression take up this ambiguity, let us first recall that, retrieving the world in its expression, Cézanne shows for Merleau-Ponty how expression is perception and how perception, which presupposes action, is always primordial expression. In expression, Cézanne is able to freely take up that which imbues his total being, making available the complete existence that is his schizothymia. The expressive operation of the body that is begun by the least perception leads into painting and any kind of art, constituting the one sole history of expression. This is why if I address myself to the other in expression-or even

\footnotetext{
19 For recent scholarship calling into question virtually every aspect of Goldstein and Gelb's case reports, see Goldenberg (2003). This critique, however, would pertain to Merleau-Ponty's method only if one were to show that the shortcomings of Gelb and Goldstein's case reports lead to an un-coherent deformation of Schneider.
} 
simply in perceiving the other - then we are already linked "without concessions" in the advent of and the desire for total manifestation that is structured by the single syntax of the gesture. The "bad ambiguity" of perception, this mixture of finitude and universality, of interiority and exteriority, of pour soi and pour autrui, throws me outside of myself and is overcome in the "good ambiguity" of expression that spontaneously gathers together into a single whole what was separate and consecrates the given to make it available to all. ${ }^{20}$

How Schneider is touched by the world is made available to Merleau-Ponty in the positive ambiguity of expression that constitutes the sole and continuous history of expression. How Schneider is grafted to the universal by that which is his most own becomes a general possibility of human existence by confronting the paradox of expression and being submitted to a coherent deformation, falling again onto the common ground of perception through the crease of speech, where Merleau-Ponty can read, in the equivalent sense delivered through language, the incomplete images of the alluding gestures for the phenomenological understanding of Schneider's total being and fundamental illness. The ambiguity of embodied perception gathered up and made whole in the ambiguity of expression in this remains an ambiguity and does never freeze into a static coincidence: just as "the absolute positing of a single object is the death of consciousness" ( $P h P 74)$, so there can be no meaning without the intercourse of signs, and the thing itself represents the end of all clarity.

Through the ambiguity of expression that gathers together into a whole what was separate and consecrates the given, we are then able to see how we are grafted to the universal by that which is most our own. This may be used, as Merleau-Ponty has done with Johann Schneider, to read the general in the particular, or (although this terminology is hardly problematized by Merleau-Ponty) the normal in the unnormal, ability in dis-ability. The ambiguity of expression made available through the continuity of expression may however also be used to grasp how these experiences are touched by the world and retrieve this world in their expression, in order to have opened a "new dimension" ( $P h P$ 188) to our own experience. Rather than seeking to isolate the general and universal, a move that is virtually presupposed in the praxis of medicine and that characterizes its "objectifying" and "scientific" gaze, Merleau-Ponty's thought equally allows us to leave intact the particularity of these experiences. When the work expresses how an experience is touched by the world, and when even science as a coherent deformation delivers us this experience in the confused clarity of an invented style, we can let ordinary ties to the world be broken in us through an upheaval in the name of another world that lies beyond claims to normalcy. If we follow Merleau-Ponty in saying that "true philosophy entails learning to see the world anew," then this possibility of a medical praxis equally represents what it means to do true philosophy, and a philosophy that, by being integrated

\footnotetext{
20 "The study of perception could only teach us a 'bad ambiguity,' a mixture of finitude and universality, of interiority and exteriority. But there is a 'good ambiguity' in the phenomenon of expression, a spontaneity which accomplishes what appeared to be impossible when we observed only the separate elements, a spontaneity which gathers together the plurality of monads, the past and the present, nature and culture, into a single whole. To establish this wonder would be metaphysics itself and would at the same time give us the principle of an ethics" (Merleau-Ponty (2007a: 290).
} 
into the advent of expression and continually falling onto the ground of perception, is also able to act beyond the antinomy of the particular and the universal.

Funding Open Access funding enabled and organized by Projekt DEAL.

Open Access This article is licensed under a Creative Commons Attribution 4.0 International License, which permits use, sharing, adaptation, distribution and reproduction in any medium or format, as long as you give appropriate credit to the original author(s) and the source, provide a link to the Creative Commons licence, and indicate if changes were made. The images or other third party material in this article are included in the article's Creative Commons licence, unless indicated otherwise in a credit line to the material. If material is not included in the article's Creative Commons licence and your intended use is not permitted by statutory regulation or exceeds the permitted use, you will need to obtain permission directly from the copyright holder. To view a copy of this licence, visit http://creativecommons.org/licen ses/by/4.0/.

\section{References}

Beringer, K. (1926). Denkstörungen und Sprache bei Schizophrenen. Zeitschrift für die gesamte Neurologie und Psychiatrie, 103(1), 185-197.

Bullington, J. (2013). The Expression of the Psychosomatic Body From a Phenomenological Perspective. Dordrecht: Springer.

Carman, T. (2012). Foreword. In M. Merleau-Ponty, Phenomenology of Perception (D. A. Landes, Trans.). New York, NY: Routledge.

Dreyfus, H. L. (2007). Reply to Romdenh-Romluc. In T. Baldwin (Ed.), Reading Merleau-Ponty: On Phenomenology of Perception (pp. 59-69). New York, NY: Routledge.

Duden, B. (1993). Disembodying Women: Perspectives on Pregnancy and the Unborn. Cambridge, MA: Harvard University Press.

Embree, L. (1980). Merleau-Ponty's Examination of Gestalt Psychology. Research in Phenomenology, $10(1), 89-120$.

Fernandez, A. V. (2019). Merleau-Ponty and the Foundations of Psychopathology. In S. Tekin, R. Bluhm (Eds.), The Bloomsbury Companion to Philosophy of Psychiatry (pp. 133-54). New York, NY: Bloomsbury Academic.

Fischer, F. (1930). Raum-Zeit-Struktur und Denkstörung in der Schizophrenie: II. Mitteilung. Zeitschrift für die gesamte Neurologie und Psychiatrie, 124(1), 241-256.

Fóti, V. M. (2013). Tracing Expression in Merleau-Ponty: Aesthetics, Philosophy of Biology, and Ontology. Evanston, IL: Northwestern University Press.

Gelb, A., \& Goldstein, K. (Eds.). (1920). Psychologische Analysen hirnpathologischer Fälle. Leipzig: Johann Ambrosius Barth.

Gill, J. H. (1990). Merleau-Ponty, Metaphor, and Philosophy. Philosophy Today, 34(1), 48-66.

Goldenberg, G. (2003). Goldstein and Gelb's Case Schn.: A Classic Case in Neuropsychology? In C. Code, Y. Joanette, A. R. Lecours, \& C.-W. Wallesch (Eds.), Classic Cases in Neuropsychology (pp. 281-299). London: Psychology Press.

Heelan, P. A. (2001). The Lifeworld and Scientific Interpretation. In S. Kay Toombs (Ed.), Handbook of Phenomenology and Medicine (pp. 47-66). Dordrecht: Springer.

Heidegger, M. (2001). Zollikon Seminars: Protocols, Conversations, Letters (M. Boss, Ed.; F. Mayr \& R. Askay, Trans.). Evanston, IL: Northwestern University Press.

Heinämaa, S. (2002). From Decisions to Passions: Merleau-Ponty's Interpretation of Husserl's Reduction. In T. Toadvine \& L. Embree (Eds.), Merleau-Ponty's Reading of Husserl (pp. 127-46). Dordrecht: Kluwer Academic Publishers.

Heinämaa, S. (2009). Phenomenological Responses to Gestalt Psychology. In S. Heinämaa \& M. Reuter (Eds.), Psychology And Philosophy (pp. 263-84). Dordrecht: Springer.

Jensen, R. T. (2009). Motor Intentionality and the Case of Schneider. Phenomenology and the Cognitive Sciences, 8(3), 371-388. 
Kelly, S. (2000). Grasping at Straws: Motor Intentionality and the Cognitive Science of Skillful Action. In M. Wrathall \& J. Malpas (Eds.), Heidegger, Coping, and Cognitive Science: Essays in Honor of Hubert L. Dreyfus - Vol. II (pp. 161-177). Cambridge, MA: MIT Press.

Landes, D. A. (2013a). Merleau-Ponty and the Paradoxes of Expression. New York, NY: Bloomsbury Academic.

Landes, D. A. (2013b). The Merleau-Ponty Dictionary. New York, NY: Bloomsbury Academic.

Leder, D. (1990). The Absent Body. Chicago, IL: University of Chicago Press.

Matherne, S. (2014). The Kantian Roots of Merleau-Ponty's Account of Pathology. British Journal for the History of Philosophy, 22(1), 124-149.

Merleau-Ponty, M. (1968). The Visible and the Invisible, Followed by Working Notes (C. Lefort, Ed.; A. Lingis, Trans.). Evanston, IL: Northwestern University Press.

Merleau-Ponty, M. (2005). Phénoménologie de la perception. Paris: Gallimard.

Merleau-Ponty, M. (2007a). An Unpublished Text by Maurice Merleau-Ponty: A Prospectus of His Work. In T. Toadvine \& L. Lawlor (Eds.), The Merleau-Ponty Reader. Evanston, IL: Northwestern University Press.

Merleau-Ponty, M. (2007b). Cézanne's Doubt. In T. Toadvine \& L. Lawlor (Eds.), The Merleau-Ponty Reader. Evanston, IL: Northwestern University Press.

Merleau-Ponty, M. (2007c). Indirect Language and the Voices of Silence. In T. Toadvine \& L. Lawlor (Eds.), The Merleau-Ponty Reader. Evanston, IL: Northwestern University Press.

Merleau-Ponty, M. (2010). Child Psychology and Pedagogy: The Sorbonne Lectures (1949-52) (T. Welsh, Trans.). Evanston, IL: Northwestern University Press.

Merleau-Ponty, M. (2012). Phenomenology of Perception (D. A. Landes, Trans.). New York, NY: Routledge.

Ricœur, P. (1979). The Function of Fiction in Shaping Reality. Man and World, 12(2), 123-141.

Romdenh-Romluc, K. (2007). Merleau-Ponty and the Power to Reckon With the Possible. In T. Baldwin (Ed.), Reading Merleau-Ponty: On Phenomenology of Perception (pp. 44-58). New York, NY: Routledge.

Schmidt, J. (1985). Maurice Merleau-Ponty: Between Phenomenology and Structuralism. London: MacMillan.

Stanghellini, G, Matthew B, Fernandez, A. V., Rosfort, R., Raballo, A., \& Fusar-Poli, P. (Eds.). (2019). The Oxford Handbook of Phenomenological Psychopathology. Oxford: Oxford University Press.

Tekin, S., \& Bluhm, R. (Eds.). (2019). The Bloomsbury Companion to Philosophy of Psychiatry. New York, NY: Bloomsbury Academic.

Toadvine, T., \& Embree, L. (Eds.). (2002). Merleau-Ponty's Reading of Husserl. Dordrecht: Kluwer Academic Publishers.

Toombs, S. K. (Ed.). (2001). Handbook of Phenomenology and Medicine. Dordrecht: Springer.

Varela, F. J., Thompson, E., \& Rosch, E. (1991). The Embodied Mind: Cognitive Science and Human Experience. Cambridge, MA: MIT Press.

Young, K. G. (1997). Presence in the Flesh: The Body in Medicine. Cambridge, MA: Harvard University Press.

Zaner, R. M. (1981). The Context of Self: A Phenomenological Inquiry Using Medicine as a Clue. Athens, OH: Ohio University Press.

Publisher's Note Springer Nature remains neutral with regard to jurisdictional claims in published maps and institutional affiliations. 